\title{
SURVEY FISIOTERAPI KESEHATAN WANITA DI BANJAR KAYEHAN DESA DAWAN KALER KECAMATAN DAWAN KLUNGKUNG
}

\author{
M.H.S. Nugraha ${ }^{1}$, N.L.N. Andayani²
}

\begin{abstract}
ABSTRAK
Pembangunan nasional dalam bidang kesehatan memiliki tujuan dalam hal pembangunan manusia agar terwujud derajat kesehatan yang optimal bagi setiap individu dalam mewujudkan bangsa yang maju dan mandiri terutama di bidang kesehatan ibu dan anak yang menjadi standar pelayanan minimal kesehatan. Pelaksanan survey fisioterapi kesehatan wanita dimulai pada tahap persiapan dengan melakukan kunjungan ke Banjar Kayehan, Desa Dawan Kaler, Kecamatan Dawan, Klungkung. Survey kesehatan diaplikasikan melalui pengisian kuesioner dengan 12 butir pertanyaan. Jumlah responden yang mengikuti survey fisioterapi kesehatan wanita berjumlah 45 orang. Hasil survey menunjukkan bahwa: (1) dari 45 responden, 33 responden belum mengalami menopause sedangkan 12 responden sudah mengalami menopause, (2) dari 45 responden, 29 orang mengalami sakit/nyeri ketika menstruasi sedangkan 16 orang tidak mengalami sakit/nyeri ketika menstruasi, (3) dari 45 responden, 8 responden mengalami keluhan saat hamil antara lain: tangan kesemutan, mual-mual, pusing, tekanan darah rendah, nyeri, dan terjadi pendarahan, (4) dari 45 responden, 35 responden tidak merasakan sakit disekitar pinggang, pinggul atau panggul setelah melahirkan dan 10 responden merasakan sakit pinggang, pinggul atau panggul setelah melahirkan, dan (5) dari 45 responden, 6 responden mengalami diastasis rektus dan 39 responden tidak mengalami diastasis rektus.
\end{abstract}

Kata kunci : fisioterapi, kesehatan wanita, survey

\begin{abstract}
National development in the health sector that has a goal in terms of human development in order to realize an optimal degree of health for each individual in realizing an advanced and independent nation, especially in the field of maternal and child health which is a minimum standard of health care. The implementation of a physiotherapy survey for women's health began in the preparation phase by visiting Banjar Kayehan, Dawan Kaler Village, Dawan District, Klungkung. The health survey was applied through filling out a questionnaire with 12 questions. The number of respondents who took a women's health physiotherapy survey was 45 people. The survey results show that: (1) from 45 respondents, 33 respondents had not experienced menopause while 12 respondents had experienced menopause, (2) from 45 respondents, 29 people experienced pain during menstruation while 16 people did not experience pain during menstruation, (3) from 45 respondents, 8 respondents experienced complaints during pregnancy including: tingling hands, nausea, dizziness, low blood pressure, pain, and bleeding, (4) from 45 respondents, 35 respondents did not feel pain around the waist, hip or pelvis after giving birth and 10 respondents felt low back pain, hip or pelvis after giving birth, and (5) from 45 respondents, 6 respondents experienced rectus diastasis and 39 respondents did not experience rectus diastasis.
\end{abstract}

Keywords: physiotherapy, women's health, survey

\footnotetext{
${ }^{1}$ Departemen Fisioterapi Fakultas Kedokteran Universitas Udayana, hendra_satria@unud.ac.id

2 Departemen Fisioterapi Fakultas Kedokteran Universitas Udayana, nopiandayani@unud.ac.id
} 


\section{PENDAHULUAN}

Pembangunan nasional dalam bidang kesehatan memiliki tujuan dalam hal pembangunan manusia agar terwujud derajat kesehatan yang optimal bagi setiap individu dalam mewujudkan bangsa yang maju dan mandiri. Kebijaksaan ini diaplikasikan melalui penerapan hidup sehat oleh masyarakat, sehingga diperlukan upaya peningkatan kesehatan yang meliputi: promotif dan pencegahan penyakit terutama di bidang kesehatan ibu dan anak yang menjadi standar pelayanan minimal kesehatan (Wahyuni, 2010). Wanita sepanjang daur hidupnya mengalami fase mulai dari menstruasi sampai menopause. Tidak jarang terdapat suatu ketidaknyamanan fisik saat menstruasi yang disebut sebagai dismenore. Dismenore merupakan nyeri menusuk yang dirasakan pada bagian bawah perut. Ketidakseimbangan hormone progesterone dalam darah menjadi penyebab timbulnya nyeri saat menstruasi (Sadjarwo, 2016).

Selain itu, fase kehamilan menyebabkan seorang wanita rentan mengalami kondisi seperti diastasis rektis abdominis. Hal ini merupakan suatu kondisi pemisahan otot rectus abdominis lebih dari $2,5 \mathrm{~cm}$ tepat setinggi umbilicus akibat dari pengaruh hormone terhadap linea alba dan peregangan mekanis dinding abdomen. Jaringan ikat mengalami kelemahan dan lebih tipis akibat adanya tekanan abdomen selama kehamilan. Selain itu, peningkatan beban di bagian tubuh akan mengakibatkan perubahan postur tubuh yang biasanya disertai oleh nyeri punggung bagian bawah (Estiani dan Aisyah, 2018).

Menopause juga menjadi permasalahan wanita yang telah berakhir masa menstruasi atau haid. Kejadian ini diawali pada usia 40 tahun dan mencapai puncak pada usia 50 tahunan. Gejala yang menyertai menopause, meliputi: kelelahan, insomnia, sakit dan nyeri pada persendian, sakit kepala, berat badan bertambah, terasa panas dan keringat di malam hari. Selain itu, menopause turut disertai dengan gangguan psikologis seperti: kecemasan, mudah tersinggung, penurunan memori ingatan, stress, mudah tersinggung, dan depresi (Pratiwi, 2014).

Fisioterapi kesehatan wanita bergerak dalam bidang pelayanan kesehatan dalam hal mengembangkan, memelihara, serta memulihkan gerak dan fungsi tubuh sepanjang daur kehidupan dengan berfokus pada penanganan secara manual, peningkatan gerak, pelatihan fungsional, penggunaaan alat atau modalitas terapi, dan komunikasi efektif. Selain itu, upaya promotive dan pencegahan dibutuhkan dalam hal dapat memetakan permasalahan yang tepat yang dialami oleh wanita yang telah memasuki fase reproduksi serta menopause (Sadjarwo, 2016).

\section{METODE PELAKSANAAN}

Pelaksanan survey fisioterapi kesehatan wanita dimulai pada tahap persiapan dengan melakukan kunjungan ke Banjar Kayehan, Desa Dawan Kaler, Kecamatan Dawan, Klungkung untuk melakukan perijinan, serta survey terkait dengan informasi awal yang diperlukan. Pada tahap ini, melibatkan beberapa staff dosen dan juga mahasiswa di Program Studi Sarjana Fisioterapi dan Profesi Fisioterapi FK Unud. Pada tahap ini, luaran yang diharapkan adalah terjalinnya kerja sama antara Program Studi Sarjana Fisioterapi dan Profesi Fisioterapi FK Unud dengan pihak Banjar Kayehan, Desa Dawan Kaler, Kecamatan Dawan, Klungkung serta terciptanya strategi pemecahan masalah terhadap tujuan pengabdian masyarakat yang akan dilakukan. Survey kesehatan dilaksanakan dengan melibatkan mahasiswa Program Studi Sarjana Fisioterapi dan Profesi Fisioterapi FK Unud sebagai tim lapangan untuk terjun langsung ke rumah warga melakukan pengisian kuesioner.

Survey kesehatan diaplikasikan melalui pengisian kuesioner dengan 12 butir pertanyaan. Pertanyaan kuesioner tersebut, terdiri atas: (1) Apakah Saudari sudah mengalami menopause? (2) Apakah menstruasi Saudari lancar? (3) Apakah pernah merasa sakit/nyeri ketika menstruasi? (4) Aktivitas seperti apa saja dilakukan ketika menstruasi? (5) Apakah Saudari mengalami obesitas? (BMI>30) (6) Apakah Saudari sedang hamil? (7) Jika Ya, kehamilan keberapa? (8) Apakah saat hamil ada keluhan yang dirasakan? (9) Jika Ya, keluhan seperti apa yang dirasakan? (10) 
Bagaimana proses persalinan saat Saudari melahirkan? (normal atau caesar) (11) Apakah setelah melahirkan merasakan sakit disekitar pinggang, pinggul atau panggul? (12) Apakah Saudari mengalami diastasis rektus? (pelebaran berlebihan atau pemisahan otot rektus abdominis lebih dari $2,5 \mathrm{~cm}$ pada tepat setinggi umbilikus akibat pengaruh hormon atau peregangan mekanis dinding abdomen/perut).

\section{HASIL DAN PEMBAHASAN}

Jumlah responden yang mengikuti survey fisioterapi kesehatan wanita berjumlah 45 orang. Hasil terkait survey, dipaparkan pada tabel 3.1 berikut.

Tabel 3.1. Hasil Pemeriksaan Survey Fisioterapi Kesehatan Wanita

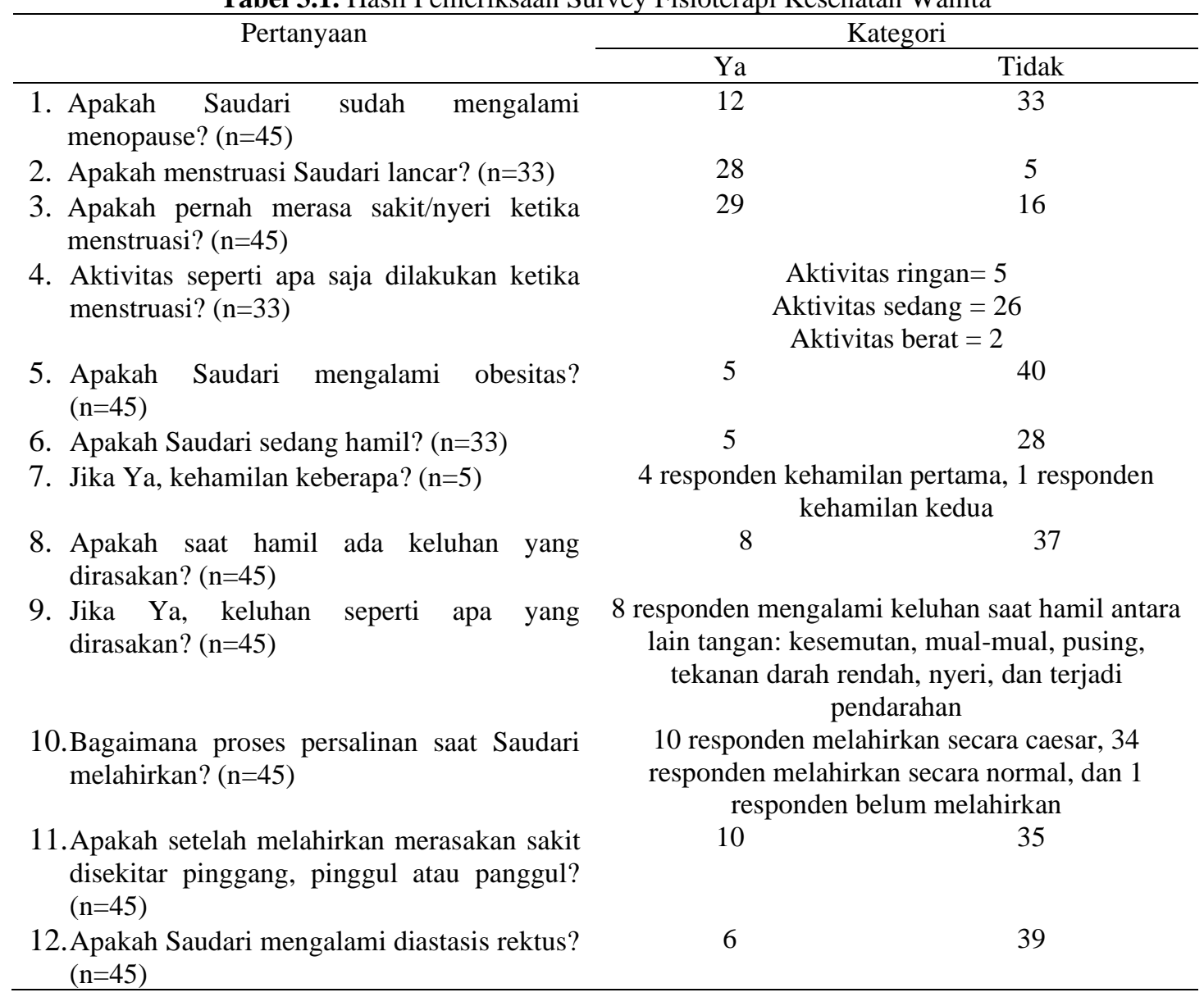

Berdasarkan tabel 3.1 maka, dapat dijelaskan bahwa: (1) Dari 45 responden, 33 responden belum mengalami menopause sedangkan 12 responden sudah mengalami menopause. (2) Dari 33 responden yang belum mengalami menopause, 28 orang mengalami menstruasi yang lancar dan 5 orang mengalami menstruasi tidak lancar. (4) dari 45 responden. 29 orang mengalami sakit/nyeri ketika menstruasi sedangkan 16 orang tidak mengalami sakit/nyeri ketika menstruasi. (5) Dari 33 responden yang belum mengalami menopause, 5 responden melakukan aktivitas yang ringan, 26 responden melakukan aktivitas yang sedang, dan 2 responden melakukan aktivitas yang berat. (6) Dari 45 responden, 5 responden mengalami obesitas. (7) Dari 33 responden yang belum mengalami menopause, 5 responden sedang hamil. Dari 5 responden yang sedang hamil, 4 responden mengalami kehamilan pertama, 1 responden mengalami kehamilan kedua. (8) dan (9) Dari 45 responden, 8 responden mengalami keluhan saat hamil antara lain tangan kesemutan, mual-mual, pusing, tekanan darah rendah, nyeri, dan terjadi pendarahan. (10) Dari 45 responden, 10 responden melahirkan secara caesar, 34 responden melahirkan secara normal, dan 1 responden belum 
melahirkan. (11) Dari 45 responden, 35 responden tidak merasakan sakit disekitar pinggang, pinggul atau panggul setelah melahirkan dan 10 responden merasakan sakit pinggang, pinggul atau panggul setelah melahirkan. (12) Dari 45 responden, 6 responden mengalami diastasis rektus dan 39 responden tidak mengalami diastasis rektus.

Berikut dokumentasi terkait survey fisoterapi kesehatan wanita yang telah dilakukan.

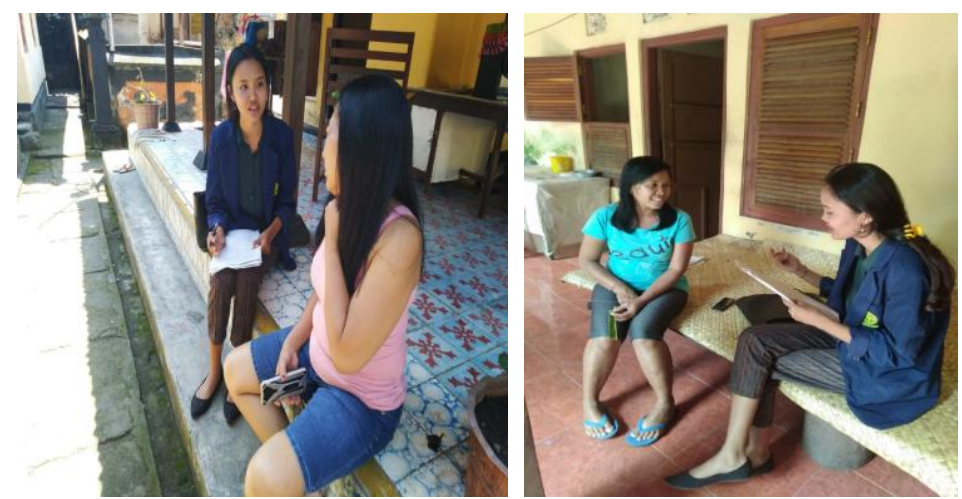

Gambar 3.1. (a) dan (b) Survey Fisioterapi Kesehatan Wanita oleh Tim Pembantu Lapangan

\section{KESIMPULAN DAN SARAN}

Berdasarkan hasil dan pembahasan di atas, maka dapat disimpulkan bahwa:

1) Dari 45 responden, 33 responden belum mengalami menopause sedangkan 12 responden sudah mengalami menopause.

2) Dari 45 responden, 29 orang mengalami sakit/nyeri ketika menstruasi sedangkan 16 orang tidak mengalami sakit/nyeri ketika menstruasi.

3) Dari 45 responden, 8 responden mengalami keluhan saat hamil antara lain: tangan kesemutan, mual-mual, pusing, tekanan darah rendah, nyeri, dan terjadi pendarahan.

4) Dari 45 responden, 35 responden tidak merasakan sakit disekitar pinggang, pinggul atau panggul setelah melahirkan dan 10 responden merasakan sakit pinggang, pinggul atau panggul setelah melahirkan.

5) Dari 45 responden, 6 responden mengalami diastasis rektus dan 39 responden tidak mengalami diastasis rektus.

\section{UCAPAN TERIMA KASIH}

Terima kasih penulis ucapkan kepada Program Studi Sarjana Fisioterapi, Profesi Fisioterapi FK Unud serta Himpunan Mahasiswa Fisioterapi FK Unud atas kerjasamanya sebagai tim surveyor survey fisioterapi kesehatan wanita.

\section{DAFTAR PUSTAKA}

Estiani, M dan Aisyah. 2018. Faktor-Faktor yang Berhubungan dengan Kejadian Diastasis Rekti Abdominis pada Ibu Post Partum di Wilayah Kerja UPTD Puskesmas Sukaraya Baturaja. Jurnal Keperawatan Sriwijaya: 5(2)

Pratiwi, SD. 2014. Hubungan antara Kecemasan dengan Fungsi Seksual pada Wanita Menopause Usia 56-60 Tahun (Skripsi). Surakarta: UMS

Sadjarwo, GMF. 2016. Pengaruh Latihan Senam Dismenore terhadap Nyeri Dismenore pada Mahasiswi Fisioterapi di Universitas 'Aisyiyah Yogyakarta (Skripsi). Yogyakarta: Universitas 'Aisyiyah

Wahyuni, S. 2010. Penatalaksanaan Terapi Latihan pada Post-Operasi Section Caesarean atas Indikasi Hamil Preterem Pree Eklamsia Ringan di RSUD Dr Moewardi Surakarta (Karya Tulis Ilmiah). Surakarta: UMS 